\title{
Chemistry and antifungal potential of Alantolides from Inula racemosa $\mathbf{H}$
}

\author{
DALVIR KATARIA and K K CHAHAL* \\ Department of Chemistry, Punjab Agricultural University, Ludhiana 141 004, India \\ e-mail: drkkchahal@yahoo.com
}

MS received 28 February 2012; accepted 16 May 2012

\begin{abstract}
Alantolactone and isoalantolactone were isolated from powdered roots of Inula racemosa $\mathrm{H}$. using Soxhlet extraction followed by the column chromatography. Pyrazolines of alantolactone and isoalantolactone were synthesized using diazomethane, diazoethane and diazopropane. The structure elucidation of the compounds were carried out using IR and ${ }^{1} \mathrm{H}$ NMR spectroscopic techniques. All the compounds were screened in vitro for their antifungal potential at various concentrations against Alternaria brassicae and Penicillium italicum using spore germination inhibition technique and against Rhizoctonia solani by poisoned food technique. All the compounds exhibited fairly good fungitoxicity against the test fungi with $\mathrm{ED}_{50}$ values of less than $500 \mu \mathrm{g} \mathrm{mL}^{-1}$.
\end{abstract}

Keywords. Alantolactone; isoalantolactone; fungitoxicity; Alternaria brassicae; Penicillium italicum; Rhizoctonia solani.

\section{Introduction}

A lactone is a type of cyclic ester. Sesquiterpene lactones are mainly found in compositae family. ${ }^{1,2}$ Sesquiterpenoids are marvellously varied group of compounds have challenged the intelligence and technical skill of chemists and biochemists interested in structure, chemistry, synthesis and biological origin. Inula racemosa, commonly known as Pushkarmoola, is a plant of wide medicinal importance which belongs to family Asteraceae and has its origin in temperate and Alpine Western Himalayas. The plant contains eudesmanolide group of sesquiterpene lactones ${ }^{3}$ namely, alantolactone (1) and isoalantolactone (2) as major components are known to exhibit wide variety of biological activities which include antispasmodic, ${ }^{3}$ hypoglycaemic activity, ${ }^{4}$ antifungal ${ }^{5-11}$ and antimalarial. ${ }^{12}$ Sesquiterpene lactones on reaction with diazomethane afforded crystalline pyrazoline derivative besides other products. ${ }^{13}$ A few reports are available on the antifungal activity of compounds isolated from Inula racemosa, but no work has been reported on the evaluation of alantolactone (1) and isoalantolactone (2) and their derivatives for antifungal activity against Alternaria brassicae, Rhizoctonia solani and Penicillium italicum.
The present work includes the chemical composition of Inula racemosa and antifungal activity of isolated compounds (1 and $\mathbf{2}$ ) and their derivatives (3-8).

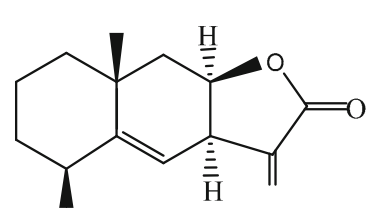

(1)

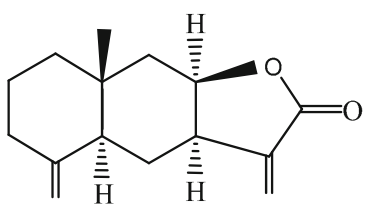

(2)

\section{Experimental}

All the melting points are uncorrected and were determined in open capillaries, on a Büchi B-545 melting point apparatus. The purity of the compounds was checked by TLC. IR spectra were measured in $\mathrm{CHCl}_{3}$ solution on Perkin Elmer, Model RX-1 FT-IR spectrophotometer. ${ }^{1} \mathrm{H}$ NMR spectra were recorded with Bruker AC (400 MHz) or mentioned otherwise as solutions (in $\mathrm{CDCl}_{3}$ ) using TMS as internal reference.

\subsection{Soxhlet extraction of Inula racemosa root oil}

The roots of Inula racemosa were obtained from the laboratory stock. The roots were dried and powdered. The root material of Inula racemosa (250 g) was

*For correspondence 
extracted by soxhlet extraction apparatus using chloroform $(1 \mathrm{~L})$ as the solvent. The soxhlet extraction was carried on for $24 \mathrm{~h}$ in two batches and the solvent was distilled off to obtain the crude extract of plant material. The chloroform extract was distilled to yield yellow oil (5 g).

\subsection{Column chromatography of extracted oil}

Extract of two batches (10 g) was collected, dissolved in $10 \mathrm{~mL}$ of chloroform and chromatographed over silica gel impregnated with silver nitrate. The column was eluted with increasing polarity of solvents (petroleum ether:dichloromethane) in a step-wise manner and the collection of fractions according to the sequence regarding the eluted products being monitored by TLC. Pure alantolactone (1) and isoalantolactone (2) were isolated from the extract by column chromatography.

\subsection{General procedure for reaction of alantolactone}

(1) with diazomethane, diazoethane and diazopropane

To the solution of alantolactone $(\mathbf{1}, 2 \mathrm{~g})$ in ether containing 2-3 drops of triethylamine was added in excess etheral solution of diazomethane. It was kept overnight. After completion of reaction as checked by TLC, the solvent was evaporated to afford crystalline compound $(3,1.4 \mathrm{~g})$ identified as pyrazoline $\mathrm{mp} 119^{\circ} \mathrm{C}$. Alantolactone $(1,2 \mathrm{~g})$ was treated with the diazoethane in ether and the reaction mixture was kept overnight to complete the reaction. On evaporating ether, white crystalline solid $(5,1.5 \mathrm{~g})$ was obtained having $\mathrm{mp} 121^{\circ} \mathrm{C}$. To the solution of alantolactone $(1,2 \mathrm{~g})$ in ether containing 2-3 drops of triethylamine was added in excess etheral solution of diazopropane. The solution was kept overnight. After completion of reaction (TLC) the solvent was evaporated to afford crystalline compound ( 7 , $1.2 \mathrm{~g}$ ) identified as pyrazoline.
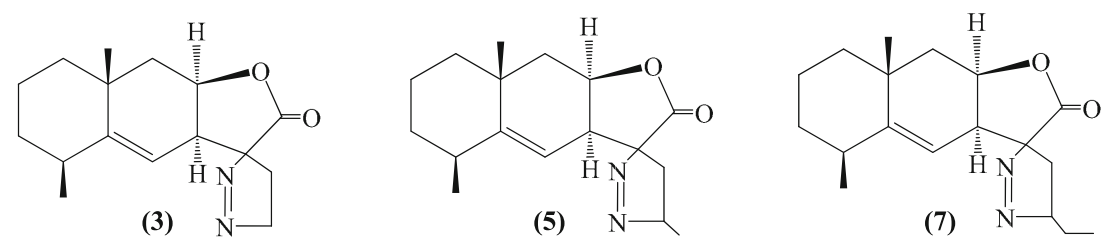

\subsection{General procedure for reaction of} isoalantolactone (2) with diazomethane, diazoethane and diazopropane

To the solution of isoalantolactone $(2,2 \mathrm{~g})$ in ether containing 2-3 drops of triethylamine was added in excess etheral solution of diazomethane. The solution was kept overnight. The solvent was evaporated to afford compound $(4,1.6 \mathrm{~g})$ which was purified by crystallization. Isoalantolactone $(2,2 \mathrm{~g})$ was treated with the diazoethane in ether and the reaction mixture was kept overnight to complete the reaction. On evaporating ether, white crystalline solid $(\mathbf{6}, 1.4 \mathrm{~g})$ was obtained having $\mathrm{mp} 109^{\circ} \mathrm{C}$. To the solution of isoalantolactone $(2,2 \mathrm{~g})$ in ether containing 2-3 drops of triethylamine was added in excess etheral solution of diazopropane. It was kept overnight. After completion of reaction as shown TLC, the solvent was evaporated which afforded crystalline compound $(\mathbf{8}, 1.3 \mathrm{~g})$ identified as pyrazoline.
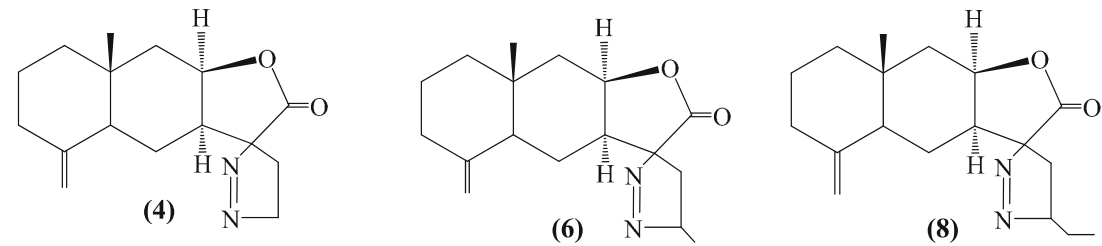

Structure of parent lactones (1 and 2) and their derivatives (3-8) were identified on the basis of IR and ${ }^{1} \mathrm{H}$ NMR spectral data (table 1 ).

\subsection{In vitro screening of compounds for fungitoxicity}

The stock solution $\left(2000 \mu \mathrm{g} \mathrm{mL}^{-1}\right)$ of test compounds and standard fungicides were prepared by dissolving 
Table 1. Spectroscopic data of alantolactone (1), isoalantolactone (2) and their derivatives (3-8).

\begin{tabular}{|c|c|c|}
\hline Compounds & $\operatorname{IR}\left(\mathrm{cm}^{-1}\right)$ & ${ }^{1} \mathrm{H} \mathrm{NMR}(\delta)$ \\
\hline () & $\begin{array}{l}1745,1665,1462,1375 \\
1262,890,810\end{array}$ & $\begin{array}{c}1.08\left(\mathrm{~d}, 3 \mathrm{H}, \mathrm{J}=7 \mathrm{~Hz}, \mathrm{C}_{4}-\mathrm{CH}_{3}\right), 5.15\left(\mathrm{~d}, 1 \mathrm{H}, \mathrm{J}=4 \mathrm{~Hz}, \mathrm{C}_{6}-\mathrm{H}\right) \\
4.81\left(\mathrm{~m}, 1 \mathrm{H}, \mathrm{C}_{8}-\mathrm{H}\right), 1.18\left(\mathrm{~s}, 3 \mathrm{H}, \mathrm{C}_{10}-\mathrm{CH}_{3}\right), 6.17(\mathrm{~d}, 1 \mathrm{H} \\
\left.\mathrm{J}=2 \mathrm{~Hz}, \mathrm{C}_{13}-\mathrm{H}\right), 5.59\left(\mathrm{~d}, 1 \mathrm{H}, \mathrm{J}=2 \mathrm{~Hz}, \mathrm{C}_{15}-\mathrm{H}\right)\end{array}$ \\
\hline & $\begin{array}{l}1760,1648,1470,1262 \\
890,880,815\end{array}$ & $\begin{array}{l}0,82\left(\mathrm{~s}, 3 \mathrm{H}, \mathrm{C}_{10}-\mathrm{CH}_{3}\right), 2.98\left(\mathrm{~m}, 1 \mathrm{H}, \mathrm{C}_{7}-\mathrm{H}\right), 4.43 \text { and } 4.76 \\
\left(\mathrm{~d}, 1 \mathrm{H} \text { each, } \mathrm{J}=1.5 \mathrm{~Hz}, \mathrm{C}_{4}-\mathrm{CH}_{2}\right), 4.51\left(\mathrm{~m}, 1 \mathrm{H}, \mathrm{C}_{8}-\mathrm{H}\right) \\
5.57 \text { and } 6.12\left(\mathrm{bs}, 1 \mathrm{H} \text { each, } \mathrm{C}_{15}-\mathrm{CH}_{2}\right)\end{array}$ \\
\hline & $3080,1741,610,1550$ & $\begin{array}{l}1.23\left(\mathrm{~d}, 3 \mathrm{H}, \mathrm{J}=7.76 \mathrm{~Hz}, \mathrm{C}_{15}-\mathrm{H}\right), 1.26\left(\mathrm{~s}, 3 \mathrm{H}, \mathrm{C}_{14}-\mathrm{H}\right), 1.57 \\
\left(\mathrm{~d}, 3 \mathrm{H}, \mathrm{N}-\mathrm{CH}-\mathrm{CH}_{3}, \mathrm{~J}=7.29 \mathrm{~Hz}\right), 4.76\left(\mathrm{~m}, 1 \mathrm{H}, \mathrm{C}_{8}-\mathrm{H}\right) \\
5.51\left(\mathrm{~m}, 1 \mathrm{H}, \mathrm{C}_{16}-\mathrm{H}\right)\end{array}$ \\
\hline & $\begin{array}{l}3080,1770,1685,1540 \\
\quad 1210,880\end{array}$ & $\begin{array}{l}0.82\left(3 \mathrm{H}, \mathrm{s}, \mathrm{C}_{14}-\mathrm{H}\right), 4.45\left(\mathrm{~m}, 1 \mathrm{H}, \mathrm{C}_{8}-\mathrm{H}\right), 1.55(\mathrm{~d}, 3 \mathrm{H} \\
\left.\mathrm{J}=7.29 \mathrm{~Hz}, \mathrm{C}_{17}-\mathrm{H}\right), 4.74-4.85\left(\mathrm{~m}, 2 \mathrm{H}, \mathrm{C}_{15}-\mathrm{H}\right) \\
5.57\left(1 \mathrm{H}, \mathrm{m}, \mathrm{C}_{16}-\mathrm{H}\right)\end{array}$ \\
\hline (1) & $3085,1750,1630,1540$ & $\begin{array}{l}1.15(\mathrm{~d}, 3 \mathrm{H}, \mathrm{J}=7 \mathrm{~Hz}, \mathrm{C} 17-\mathrm{H}), 1.21(\mathrm{~d}, 3 \mathrm{H}, \mathrm{J}=7.76 \mathrm{~Hz} \\
\mathrm{C} 15-\mathrm{H}), 1.25(\mathrm{~s}, 3 \mathrm{H}, \mathrm{C} 14-\mathrm{H}), 4.10 \& 4.90(\mathrm{dd}, 1 \mathrm{H} \text { each, } \\
\mathrm{J}=10 \text { and } 18 \mathrm{~Hz}, \mathrm{C} 16-\mathrm{H} \text { 's), } 4.76(\mathrm{~m}, 1 \mathrm{H}, \mathrm{C} 8-\mathrm{H})\end{array}$ \\
\hline (6) & $\begin{array}{l}3080,1770,1685,1540 \\
1210 \& 880\end{array}$ & $\begin{array}{l}1.10\left(\mathrm{~s}, 3 \mathrm{H}, \mathrm{C}_{14}-\mathrm{H}\right), 1.50\left(\mathrm{~d}, 3 \mathrm{H}, \mathrm{C}_{17}-\mathrm{H}, \mathrm{J}=7.2 \mathrm{~Hz}\right) \\
4.50\left(\mathrm{~m}, 1 \mathrm{H}, \mathrm{C}_{8}-\mathrm{H}\right), 4.20 \& 5.00(\mathrm{dd}, 1 \mathrm{H} \text { each, } \\
\left.\mathrm{J}=10 \text { and } 18 \mathrm{~Hz}, \mathrm{C}_{16}-\mathrm{H} \text { 's }\right), 4.75\left(\mathrm{bs}, 1 \mathrm{H} \text { each, } \mathrm{C}_{15}-\mathrm{H} ' \mathrm{~s}\right)\end{array}$ \\
\hline (7) & $3070,1745,1670,1555$ & $\begin{array}{l}1.14\left(\mathrm{t}, 3 \mathrm{H}, \mathrm{J}=7.2 \mathrm{~Hz}, \mathrm{C}_{18}-\mathrm{H}\right), 1.22(\mathrm{~d}, 3 \mathrm{H}, \mathrm{J}=7.74 \mathrm{~Hz} \\
\left.\mathrm{C}_{15}-\mathrm{H}\right), 1.27\left(\mathrm{~s}, 3 \mathrm{H}, \mathrm{C}_{14}-\mathrm{H}\right), 4.10 \& 4.90(\mathrm{dd}, 1 \mathrm{H} \text { each, } \\
\mathrm{J}=10 \text { and } 18 \mathrm{~Hz}, \mathrm{C}_{16}-\mathrm{H} \text { 's), } 4.76\left(\mathrm{~m}, 1 \mathrm{H}, \mathrm{C}_{8}-\mathrm{H}\right)\end{array}$ \\
\hline (8) & $\begin{array}{l}3080,1765,1675,1545 \\
1225 \& 890\end{array}$ & $\begin{array}{l}1.12\left(\mathrm{~s}, 3 \mathrm{H}, \mathrm{C}_{14}-\mathrm{H}\right), 1.20\left(\mathrm{t}, 3 \mathrm{H}, \mathrm{C}_{18}-\mathrm{H}, \mathrm{J}=7.29 \mathrm{~Hz}\right) \\
4.51\left(\mathrm{~m}, 1 \mathrm{H}, \mathrm{C}_{8}-\mathrm{H}\right), 4.10 \& 4.90(\mathrm{dd}, 1 \mathrm{H} \text { each, } \\
\left.\mathrm{J}=10 \text { and } 18 \mathrm{~Hz}, \mathrm{C}_{16}-\mathrm{H} \text { 's }\right), 4.76\left(\mathrm{bs}, 1 \mathrm{H} \text { each, } \mathrm{C}_{15}-\mathrm{H} ' \mathrm{~s}\right)\end{array}$ \\
\hline
\end{tabular}

the compound $(20 \mathrm{mg})$ in acetone $(0.5 \mathrm{~mL})$ and volume was made to $10 \mathrm{~mL}$ with distilled water. The further concentrations were made by adding distilled water.

Antifungal activity was tested by means of spore germination inhibition technique. ${ }^{1}$ Ten-day old cultures of the test fungi (Alternaria brassicae and Penicillium italicum) were taken from PDA slants and spore suspension was made by adding sterilized distilled water. Small droplets $(0.02 \mathrm{~mL})$ of test solution and spore suspension in equal amount were seeded in the cavities of the cavity slides. These slides were placed in petriplates lined with moist filter paper and were incubated for $20 \mathrm{~h}$ 
at $24 \pm 1{ }^{\circ} \mathrm{C}$. The number of spores germinated were counted and per cent spore germination inhibition was calculated using the formula

Percent spore germination inhibition

$$
\begin{aligned}
= & \frac{\text { Spore germination in control }- \text { Spore germination in treated }}{\text { Spore germination in control }} \\
& \times 100 .
\end{aligned}
$$

For Rhizoctonia solani antifungal activity was tested by means of Poisoned food technique. ${ }^{5}$ Approximately $99 \mathrm{~mL}$ of PDA media was taken in the round bottom flasks, $1 \mathrm{~mL}$ (different concentrations) of each compound was added to different flasks and the contents were mixed thoroughly. The contents of the flask were poured aseptically into the petriplates. Test compound was however, replaced by an equal amount of acetone only in the control set. After the media solidified one inoculum disc of Rhizoctonia solani mycelium, the test fungus, was aseptically placed/inoculated to each petriplate and incubated at $24 \pm 1{ }^{\circ} \mathrm{C}$. The average diameter of fungal colonies was measured on the $7^{\text {th }}$ day after inoculation and percentage mycelial growth inhibition was calculated using the formula

$$
\begin{aligned}
& \text { Percent mycelial growth inhibition } \\
& =\frac{\text { Mycelial growth in control }- \text { Mycelial growth in treated }}{\text { Mycelial growth in control }} \times 100 \text {. }
\end{aligned}
$$

\section{Results and discussion}

\subsection{Spectral analysis}

Pyrazoline derivatives of alantolactone (1) and isoalantolactone (2) were synthesized by their reaction with diazomethane when crystalline compounds (3 and 4) were formed. The IR spectrum of alantolactone (1) showed bands at $1745 \mathrm{~cm}^{-1}$ due to the presence of $\gamma$ lactone moiety, band at 1610 attributes to $\mathrm{C}=\mathrm{C}$ stretch, band at $890 \mathrm{~cm}^{-1}$ due to $=\mathrm{C}-\mathrm{H}$ bending (table 1 ). The $\mathrm{H}^{1} \mathrm{NMR}$ spectrum of alantolactone (1) showed doublet at $\delta 1.11$ due to $\mathrm{C}_{4}-\mathrm{CH}_{3}$, single proton at $\mathrm{C}_{6}$ displaying a singlet at $\delta 5.37, \delta 4.81$ signal due to lactone moiety at $\mathrm{C}_{8}$ which have one $\alpha$-substituent and methylenic double band around $5.59 \delta$ and $6.17 \delta$. The only difference in the structures of isoalantolactone (2) from alantolactone (1) exocyclic double bond at $\mathrm{C}_{4}$ gives doublet signals at $\delta 4.83$ and 5.03 corresponds to $2 \mathrm{H}$ of $\mathrm{CH}_{2}$. The diazomethane derivatives of parent lactones gives the IR bands for $\mathrm{N}=\mathrm{N}$ stretch at $1550 \mathrm{~cm}^{-1}$ and $\mathrm{H}^{1} \mathrm{NMR}$ band of $-\mathrm{CH}_{2}-\mathrm{N}=$ at $\delta 4.10$ was observed. Similar reaction of alantolactone (1) and isoalantolactone
(2) was carried out with diazoethane and compounds (5 and 6) were formed, respectively. The diazoethane derivatives of parent lactones gives $\mathrm{H}^{1} \mathrm{NMR}$ band at $\delta 0.96$ was observed due to $\mathrm{CH}_{3}$ group at $\mathrm{C}_{16}$. Diazopropane derivative (7) of alantolactone was formed and in the same way diazopropane derivative (8) of isoalantolactone was formed. The diazopropane derivatives of parent lactones $\mathrm{H}^{1} \mathrm{NMR}$ signal at $\delta 1.55$ was observed due to $\mathrm{CH}_{2}$ group at $\mathrm{C}_{16}$ and triplet signal at $\delta 0.90$ was of $\mathrm{CH}_{3}$ at $\mathrm{C}_{17}$. The biological activity of compounds is due to the exomethylene group conjugated to the lactone carbonyl. The parent lactones (1 and 2) and their derivatives (3-8) prepared were tested against Alternaria brassicae, Penicillium italicum and Rhizoctonia solani for their antifungal activity.

\subsection{Fungitoxicity of compounds}

The synthesized compounds were screened in vitro for their antifungal potential against Alternaria brassicae (Alternaria blight of rapeseed) and Penicilium italicum (Blue mould of kinnow) by using spore germination inhibition technique. The compounds were also tested against Rhizoctonia solani (Black scurf of potato) for antifungal potential using poisoned food technique.

All the compounds have shown excellent fungitoxicity against the Alternaria brassicae with $\mathrm{ED}_{50}$ values of less than $500 \mu \mathrm{g} / \mathrm{mL}$. Isoalantolactone (2) was found to be most potent against Alternaria brassicae with the $\mathrm{ED}_{50}$ value of $190 \mu \mathrm{g} / \mathrm{mL}$ (table 2). Isoalantolactone (2) and its derivatives are more fungitoxic as compared to alantolactone (1) and its derivatives. The diazopropane derivative (7) of alantolactone (1) is least fungitoxic. The diazomethane derivatives ( 3 and 4) were equally fungitoxic with $\mathrm{ED}_{50}$ value comparable with compounds ( $\mathbf{1}$ and $\mathbf{2}$ ). The compounds (5-8) showed fungitoxicity with the $\mathrm{ED}_{50}$ value more than $300 \mu \mathrm{g} / \mathrm{mL}$. The standard fungicide Indofil M45 was highly fungitoxic against Alternaria brassicae with the

Table 2. Antifungal potential of compounds.

\begin{tabular}{lccc}
\hline & \multicolumn{3}{c}{$\mathrm{ED}_{50}$ value $(\mu \mathrm{g} / \mathrm{mL})$ against } \\
\cline { 2 - 4 } Compounds & A. brassicae & P. italicum & R. solani \\
\hline $\mathbf{1}$ & 260 & 250 & 450 \\
$\mathbf{2}$ & 190 & 210 & 300 \\
$\mathbf{3}$ & 240 & 210 & 330 \\
$\mathbf{4}$ & 210 & 180 & 350 \\
$\mathbf{5}$ & 380 & 320 & 380 \\
$\mathbf{6}$ & 310 & 280 & 330 \\
$\mathbf{7}$ & 460 & 450 & 440 \\
$\mathbf{8}$ & 360 & 380 & 380 \\
\hline
\end{tabular}


$\mathrm{ED}_{50}$ value of $290 \mu \mathrm{g} / \mathrm{mL}$. The compounds (1-4) were more fungitoxic than Indofil M45 with $\mathrm{ED}_{50}$ value less than $290 \mu \mathrm{g} / \mathrm{mL}$.

All the compounds have shown excellent fungitoxicity against the test fungi with $\mathrm{ED}_{50}$ values of less than $500 \mu \mathrm{g} / \mathrm{mL}$ (table 2). The compound (4) was found to be most potent against Penicillium italicum with the $\mathrm{ED}_{50}$ value of $180 \mu \mathrm{g} / \mathrm{mL}$. Isoalantolactone (2) and its derivatives were more fungitoxic as compared to alantolactone (1) and its derivatives. The diazopropane derivative (7) of alantolactone is least fungitoxic. The diazomethane derivatives are more reactive than the other derivatives of alantolactone (1) and isoalantolactone (2). Isoalantolactone (2) and diazomethane derivatives of alantolactone are equally fungitoxic. The diazomethane derivative (4) was more fungitoxic than compound (3). Isoalantolactone (2) and diazomethane derivative of alantolactone (3) were equal fungitoxic with the $\mathrm{ED}_{50}$ value of $210 \mu \mathrm{g} / \mathrm{mL}$. The compounds $(\mathbf{5}, 7$ and 8$)$ showed fungitoxicity with the $\mathrm{ED}_{50}$ value more than $300 \mu \mathrm{g} / \mathrm{mL}$. Diazopropane derivative of alantolactone (7) was least fungitoxic with the $\mathrm{ED}_{50}$ value $450 \mu \mathrm{g} / \mathrm{mL}$. The standard fungicide Indofil M-45 was highly fungitoxic against Penicillium italicum with the $\mathrm{ED}_{50}$ value of $45 \mu \mathrm{g} / \mathrm{mL}$.

The compound (2) was found to be most potent against Rhizoctonia solani with the $\mathrm{ED}_{50}$ value of $300 \mu \mathrm{g} / \mathrm{mL}$ (table 2). Isoalantolactone (2) and its derivatives are more fungitoxic as compared to alantolactone and its derivatives. The diazomethane derivatives are more reactive than the other derivatives of alantolactone (1) and isoalantolactone (2). Diazomethane derivative of alantolactone (1) and diazoethane derivative of isoalantolactone (2) are equally reactive on the mycelial growth of Rhizoctonia solani. Compounds (1) and (7) showed almost equal fungitoxicity against Rhizoctonia solani. Diazomethane derivative of alantolactone (3) and diazoethane derivative of isoalantolactone (6) was equally fungitoxic with the $\mathrm{ED}_{50}$ value of $330 \mu \mathrm{g} / \mathrm{mL}$. Compounds (5) and (8) also showed almost same fungitoxicity against Rhizoctonia solani with the $\mathrm{ED}_{50}$ value of $380 \mu \mathrm{g} / \mathrm{mL}$.

\section{Conclusions}

The lactone moiety present in all the test compounds were responsible for the fungitoxicity of the com- pounds. The difference in their antifungal activity was due to their structural differences. The exocyclic double bond in isoalantolactone (2) at $\mathrm{C}_{4}$ is not present in alantolactone (1) which may be responsible for the more fungitoxicity of isoalantolactone (2) as compared to alantolactone (1). Diazomethane derivative of isoalantolactone (4) was more fungitoxic than diazomethane derivative of alantolactone (3) which may also be due to the presence of exocyclic double bond at $\mathrm{C}_{4}$. The diazoethane derivatives of both the lactones were less fungitoxic than diazomethane derivatives due to the presence of the methyl group $\left(\mathrm{CH}_{3}\right)$ at $\mathrm{C}_{13}$. The diazopropane derivative of alantolactone (1) and isoalantolactone (2) were least fungitoxic. It can be concluded that with the increase of length of alkyl chain at $\mathrm{C}_{13}$ by one carbon atom, the fungitoxic activity decreases against Alternaria brassicae, Penicillium italicum and Rhizoctonia solani.

It may be concluded that fungicidal potential of test compounds was increased due to (i) the presence of exocyclic double bond at $\mathrm{C}_{4}$ and (ii) less number of $-\mathrm{CH}_{3}$ groups in alkyl chain at $\mathrm{C}_{13}$.

\section{References}

1. Schmidt J, Muller E and Fronczek Frank R 2001 J. Nat. Prod. 4411

2. Spring O, Zipper R, Reeb S, Vogler B and Da Costa F B 2001 Phytochemistry 57267

3. Anonymous 1977 Suzhou Jiangsu, China 627

4. Gholap K and Kar S 2003 Phytochemistry 263359

5. Lokhande P D, Gawai K R, Kodam K M, Kuchekar B S, Chabukswar A R and Jagdale S 2007 Res. J. Medicinal Plant. 17

6. Mishra A K, Liu C H, He B and Tan R X 2000 Int. Pest Control 42(4) 131

7. Newall C, Anderson L, Phillipson D 1995 Herbal medicines. London: The Pharmaceutical Press

8. Sabanero M, Quijana L, Rios T and Trejo R 1995 Plant. Medica. 61185

9. Shea L J, McGaw L J, Aderogba M A, Mdee L K and Eloff J N 2009 J. Ethnopharmacol. 119238

10. Tan R X, Tang H Q, Hu J and Shuai B 1998 Phytochemistry 49157

11. Tani S, Fukamiya M, Kiyokawa H, Musallan H A, Pick R O and Lee Kuo Hising 1985 J. Med. Chem. 28(11) 1743

12. Xie Y S, Fields P G and Isman M B 1995 J. Econ. Entomol. 881024

13. Kalsi P S, Kaur G, Sharma S and Talwar K K 1984 Phytochemistry 23(2) 2855 